\title{
The impact of pre-filled saline flush syringes in reducing the incidence of peripheral venous catheter failure. A quasi-experimental multicenter study
}

Saliba P1, Hornero A1, de Carli G2, Marani A2, Lopez AF 3, Iftimie S 3, Castro A, 3 Diaz-Brito V 4, Jimenez C 4, Martinez JM5, Jimenez E1, Carratala J1, Pujol M1

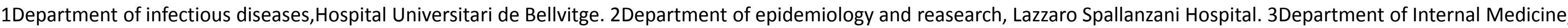

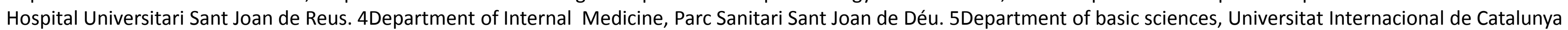

\section{BACKGROUND}

The unscheduled replacement of peripheral venous catheter (PVC) is common and frequently entails a new invasive procedure. Flushing the catheter before and after use, maintains patency and could prolong catheter dwell time. Although saline flushing is highly recommended, compliance in the daily routine care is uncertain.

\section{OBJECTIVE}

To determine whether there are significant differences in overall PVC failure rates before and after introduction of pre-filled flushing syringes and to assess risk factors for PVC failure.

\section{METHODS}

Methods: quasi-experimental design; before-and-after intervention study.

Intervention: Introduction of pre-filled saline syringes for flushing. Multicenter study conducted in medical and surgical units in 3 European hospitals for a period of 9 months $(5$ months preintervention, 4 months intervention).

Main outcome: Catheter failure, defined as a composite variable encompassing unscheduled withdrawal or replacement of PVC because of any of the following conditions: phlebitis, thrombosis extravasation, suspected infection.

Statistical analysis: A multivariate Cox proportional hazard ratio was used to identify factors associated with the occurrence of PVC failure.

\section{RESULTS}

Data were analysed for 3,853 PVCs in 1,915 patients. Overall, the incidence of PVC failure was $\mathbf{5 0 . 1 \% , ~ m a i n l y ~ d u e ~ t o ~ p h l e b i t i s ~ a n d ~}$ infiltration/extravasation. Compared to pre-intervention period, a significant decrease in PVC failure rate was observed in the intervention period (55.4\% vs 44.8\%, $\mathrm{p}<0.01$ ). Risk factors for PVC failure were: Charlson score $\geq 4$ (HR:1.64;95\%Cl:1.069-2.527), days of hospital stay $\geq 10$ (HR:1.46;95\%Cl:1.172-1.837), and the use of PVC "Type D" (HR:1.75;95\%Cl:1.05-2.91), while intervention period ( $\mathrm{HR}: 0.76 ; 95 \% \mathrm{Cl}: 0.63-0.91)$ and insertion of PVC at traumatology ward (HR:0.43;95\% $\mathrm{Cl}: 0.21-0.85)$ reduced the risk of PVC failure (Table 1).

Figure 1, shows dwell time of PVC among the period 1 and 2 . By the $5^{\text {th }}$ day of catheterization, only $40 \%$ of PVC in the period 1 survive without a failure, while $60 \%$ of PVC survive without any failure in the period 2.

\begin{tabular}{|c|c|c|c|c|c|}
\hline & $\begin{array}{c}\text { Non Catheter } \\
\text { Failure } \\
\text { N=1906 }\end{array}$ & $\begin{array}{l}\text { Catheter } \\
\text { failure } \\
\mathrm{N}=1947\end{array}$ & $\begin{array}{c}\text { P } \\
\text { Value }\end{array}$ & $\begin{array}{l}\text { Hazard } \\
\text { ratio }\end{array}$ & $\mathrm{Cl} 95 \%$ \\
\hline Age $\geq 65$ & $1176(61.7 \%)$ & 1190 (61.1\%) & 0.716 & & \\
\hline Gender (Male) & $1071(56.2 \%)$ & $1116(57.3 \%)$ & 0.495 & & \\
\hline Charlson score $\geq 4$ & 871 (45.7\%) & 1097 (56.3\%) & 0.000 & 1.644 & $1.069-2.527$ \\
\hline Days of hosp $\geq 10$ & $713(37.4 \%)$ & $1289(66.2 \%)$ & 0.000 & 1.468 & $1.172-1.837$ \\
\hline Days of cath $\geq 4$ & $993(52.1 \%)$ & 712 (36.6\%) & 0.000 & & \\
\hline \multicolumn{6}{|l|}{$\begin{array}{l}\text { Unit of } \\
\text { Hospitalisation }\end{array}$} \\
\hline trauma & $324(17 \%)$ & $86(4.4 \%)$ & 0.000 & 0.431 & $0.219-0.851$ \\
\hline \multicolumn{6}{|l|}{ Type of catheter } \\
\hline Catheter A & $1587(83.3 \%)$ & $1475(75.8 \%)$ & 0.000 & & \\
\hline Catheter B & $129(6.8 \%)$ & 104 (5.3\%) & 0.037 & & \\
\hline Catheter C & $33(1.7 \%)$ & 75 (3.9\%) & 0.000 & & \\
\hline Catheter D & $157(8.2 \%)$ & $293(15 \%)$ & 0.000 & 1.75 & $1.05-2.91$ \\
\hline \multicolumn{6}{|l|}{$\begin{array}{l}\text { Unit of } \\
\text { catheterisation }\end{array}$} \\
\hline Hospital & 1118 (58.7\%) & $1181(60.7 \%)$ & 0.212 & & \\
\hline Emergency Unit & 599 (31.4\%) & 661 (33.9\%) & 0.051 & & \\
\hline Others & 189 (9.9\%) & 105 (5.4\%) & 0.000 & & \\
\hline Charlson score $\geq 4$ & 871 (45.7\%) & 1097 (56.3\%) & 0.000 & 1.644 & $1.069-2.527$ \\
\hline Intervention period & 974 (51.1\%) & 791 (40.6\%) & 0.000 & 0.761 & $0.630-0.919$ \\
\hline
\end{tabular}

Table 1: Univariate and multivariate analysis of the risk factors associated with PVC failure

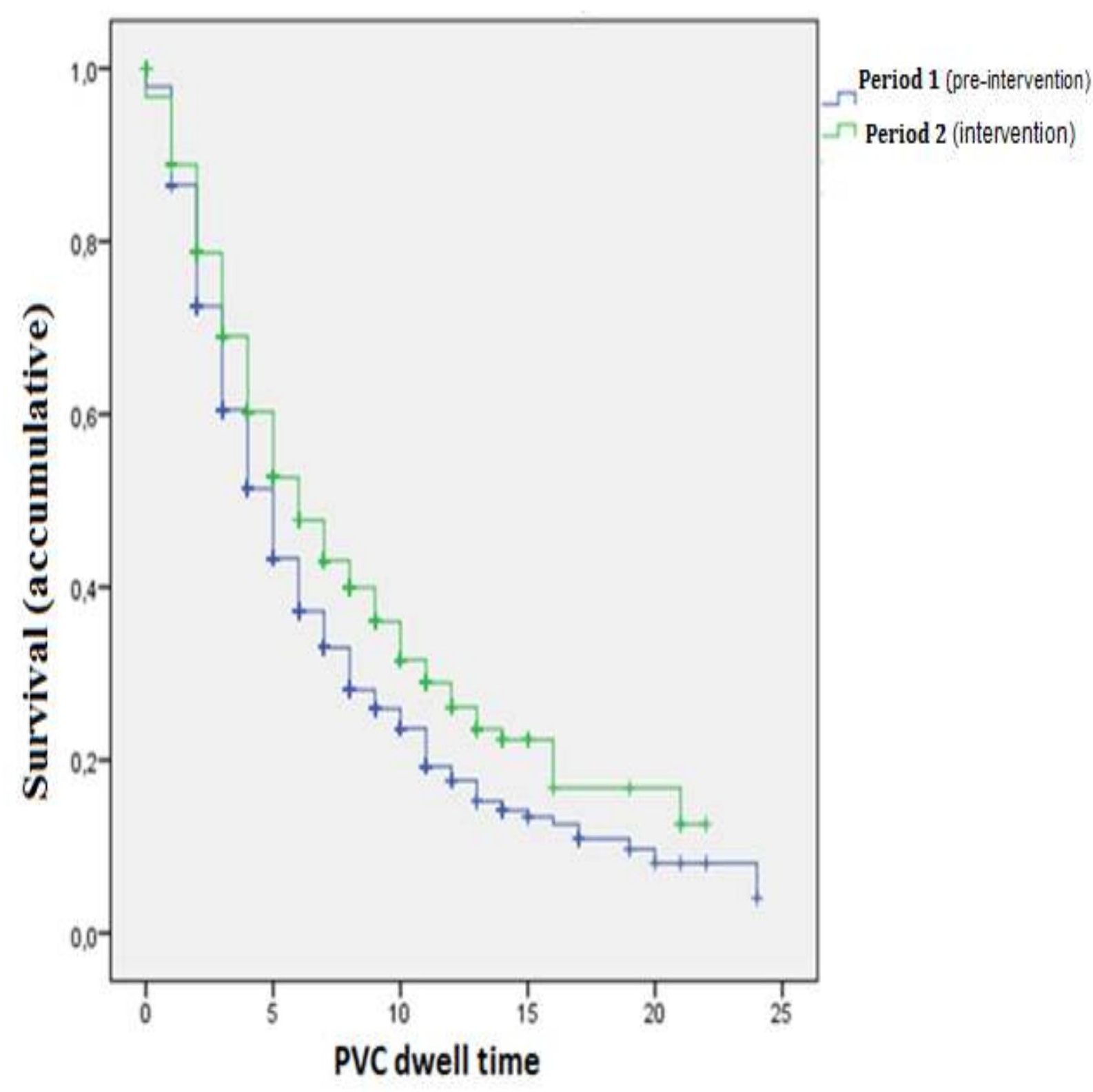

Figure 1:Kaplan meier curve showing the difference in the PVC dwell time between Period 1 and 2 .

\section{CONCLUSIONS}

We found that unscheduled PVC replacement was very high in study hospitals. The risk of catheter failure varied according to patient comorbidities, days of hospital stay, and type of PVC. The introduction of catheter flushing with pre-filled saline syringes had a significant impact on reducing unscheduled vascular catheter replacement. 